\title{
RELAÇÕES CLÍNICAS DOS CONTRACEPTIVOS ORAIS NO CURSO DA DOENÇA PERIODONTAL
}

\author{
Michelle Quintanilha Costa de MOURA ${ }^{1}$, Adolpho Marlon Antoniol de MOURA ${ }^{2 *}$, Aline Manhães PESSANHA \\ \& Diogo Elias MIQUILITO ${ }^{3}$
}

1 Serviço Social da Indústria, SESI, Departamento de Odontologia, Campos dos Goytacazes, Rio de Janeiro, Brasil. 2 Fundação Oswaldo Cruz, Instituto de Tecnologia em Imunobiológicos Bio-Manguinhos, Rio de Janeiro, Brasil.

3 Universidade Iguaçu, Campus V. Itaperuna, Rio de Janeiro, Brasil.

*Autor para correspondência: dofo.antonio178@gmail.com

DOI: http://dx.doi.org/10.18571/acbm.190

\section{RESUMO}

A saúde dos tecidos periodontais encontra-se intimamente ligada ao equilíbrio entre fatores agressores e protetores ao periodonto. Há evidências de que o uso de contraceptivos orais provocam alterações deletérias aos tecidos periodontais. Objetivou-se com esta revisão correlacionar uso de contraceptivos orais no curso da doença periodontal. Resultados controversos das pesquisas realizadas entre as décadas de 60 a 90 indicam que a concentração hormonal nos contraceptivos está intimamente correlacionada à resposta inflamatória tecidual. Atualmente, os contraceptivos orais parecem não influenciar no curso da doença periodontal, mas sim, a higienização e manutenção da saúde bucal ineficiente do paciente em inibir os agentes etiológicos associados à patologia.

Palavras chave: anticoncepcionais, gengivite, inflamação, patologia oral, periodontia.

\section{ABSTRACT}

The health of the periodontal tissues is closely linked to the balance between aggressive and protective factors to the periodontium. There is evidence that the use of oral contraceptives causes deleterious changes to the periodontal tissues. The objective of this review was to correlate the use of oral contraceptives in the course of periodontal disease. Controversial results from research conducted between the 1960s and 1990s indicate that the hormonal concentration in contraceptives is closely correlated to the tissue inflammatory response. Currently, oral contraceptives do not seem to influence the course of periodontal disease, but rather the hygiene and maintenance of the patient's inefficient oral health in inhibiting the etiological agents associated with the pathology.

Keywords: contraception, gingivitis, inflammation, oral pathology, periodontics.

\section{Introdução}

A identificação de diversos tipos de patologias gengivais associadas à secreção alterada dos hormônios sexuais tem direcionado para a associação dos efeitos hormonais sobre os tecidos periodontais e na cicatrização das lesões periodontais. Os níveis de hormônios sexuais femininos circulantes durante a gestação, puberdade, e ingestão de anticoncepcionais orais têm sido sugeridos como fatores na patogenia da doença periodontal, alterando a resposta do periodonto aos fatores etiológicos locais (CARRANZA JR et al., 2012). 
Há muitos tipos de enfermidades gengivais em que a modificação da taxa de hormônios sexuais é considerada o fator coadjuvante à placa dental como fator etiológico, podendo ocorrer tendência à hemorragia e alterações inflamatórias não específicas com um componente vascular predominante (GOLDMAN \& COHEN, 1983). Os hormônios sexuais podem exercer suas influências sobre os tecidos periodontais alterando a resposta tecidual à placa e influenciando a síntese de citocinas inflamatórias, particularmente as prostaglandinas (TUNES \& RAPP, 1999).

Os tecidos periodontais, em especial a gengiva, são considerados tecidos-alvo à ação dos hormônios esteróides e alterações clínicas do periodonto podem ser identificadas durante os períodos de flutuação hormonal (puberdade, menstruação, gravidez, menopausa, com o uso de contraceptivos hormonais ou sob efeito da terapia de reposição hormonal). Os níveis aumentados de inflamação observados nes tes períodos de flutuação podem ser resultado de uma interação de estrogênio e progesterona com mediadores da inflamação (PALMER \& SOORY, 2005). Em se tratando especificamente dos contraceptivos hormonais, CORMACK, 1993, relatou que estes são compostos por análogos sintéticos dos hormônios ovarianos e simulam um estado de gravidez, através da elevação dos níveis hormonais do plasma. Além disto, os anticoncepcionais hormonais inibem a ovulação através da supressão dos hormônios folículo-estimulante e luteinizante (secretados pela glândula hipófise anterior).

O primeiro contraceptivo hormonal foi a pílula Enovid®, contendo $150 \mu \mathrm{g}$ de mestranol (estrógeno) e 9,85 mg de noretinodrel (progesterona). Esta droga foi aprovada pela Food and Drug Administration (FDA) para uso nos Estados Unidos em 1960 e, desde então, os contraceptivos orais se tornaram a forma de contracepção hormonal reversível mais utilizada. A fim de reduzir os efeitos colaterais, os contraceptivos orais, ao longo dos anos, passaram a apresentar doses diminuídas, sobretudo de estrógeno (30-35 $\mu \mathrm{g}$ de etinil-estradiol), sem, no entanto, interferir na efetividade contraceptiva (ASRM, 2004).

Os contraceptivos orais produzem uma mudança similar à gravidez e têm sido associados ao aumento na prevalência de gengivite e no fluido do sulco gengival. Em verdade, as mudanças clínicas observadas na gengivite induzida por placa são acentuadas pelos níveis circulantes dos hormônios sexuais através de mecanismos como supressão imune parcial, aumento do exsudato, estimulação da reabsorção óssea e estimulação da atividade sintética de fibroblastos (SOORIYAMOORTHY \& GOWER, 1989). Outra modificação importante ocorre na microbiota gengival, com o aumento no número de espécies $P$. intermédia (principal espécie periodonto patogênica envolvida na periodontite agressiva). A elevação no número destes microrganismos pode estimular a síntese de prostaglandinas pelos monócitos e alterar o sistema vascular, desencadeando a formação de edema, eritema, exsudato e sangramento gengival (STEINBERG, 2001).

Considerando o biofilme o principal fator etiológico da doença periodontal, torna-se imprescindível uma atenção maior aos indivíduos do gênero feminino no sentido de ressaltar, através de orientações de higiene bucal, a importância de se manter uma condição de saúde bucal favorável, visto que a mulher está sujeita aos efeitos das variações hormonais associadas ao seu ciclo reprodutivo ou derivadas da terapia hormonal (SANTOS et al., 2008).

Objetiva-se com a presente revisão, relatar as manifestações clínicas da doença periodontal relacionadas às alterações hormonais, envolvendo o uso de contraceptivos orais.

\section{Revisão de literatura}

\subsection{Hormônios sexuais femininos}

Os hormônios ovarianos, o estrogênio e a progesterona, são responsáveis pelo desenvolvimento sexual da mulher e pelo ciclo menstrual. Esses hormônios, como os hormônios 
adrenocorticais e o hormônio masculino testosterona, são ambos compostos esteroides (GUYTON, 1998).

O estrogênio e a progesterona exercem várias funções fisiológicas. Nas mulheres, isso inclui efeitos sobre o desenvolvimento, ações neuroendócrinas envolvidas no controle da ovulação, na preparação cíclica do trato reprodutivo para a fecundação e a implantação e ações importantes sobre o metabolismo de minerais, carboidratos, proteínas e lipídios. Muitos aspectos da constituição corporal feminina também são influenciados por esses hormônios. Mais recentemente foi demonstrado que os estrogênios desempenham ações importantes nos homens, incluindo efeitos nos ossos, na espermatogênese e no comportamento(LOOSE-MITCHELL \& SYANCEL, 2003).

Segundo GUYTON (1998) os estrogênios são, na verdade, vários hormônios diferentes chamados estradiol, estriol e estrona, mas que têm funções idênticas e estruturas químicas muito semelhantes. Por esse motivo, são considerados juntos, como um único hormônio. Esse hormônio induz as células de muitos locais do organismo, a proliferar, isto é, a aumentar em número. Por exemplo, a musculatura lisa do útero, aumenta tanto que o órgão, após a puberdade, chega a duplicar ou, mesmo, a triplicar de tamanho. Também provoca o aumento da vagina e o desenvolvimento dos lábios que a circundam, faz o púbis se cobrir de pêlos, os quadris se alargarem e o estreito pélvico assumir a forma ovóide, em vez de afunilada como no homem; provoca o desenvolvimento das mamas e a proliferação dos seus elementos glandulares, e, finalmente, leva o tecido adiposo a concentraremse, na mulher, em áreas como os quadris e cochas, dando-lhes o arredondamento típico do sexo. Em resumo, todas as características que distinguem a mulher do homem são devido ao estrogênio e a razão básica para o desenvolvimento dessas características é o estímulo à proliferação dos elementos celulares em certas regiões do corpo.

A progesterona tem pouco a ver com o desenvolvimento dos caracteres sexuais femininos; está principalmente relacionada com a preparação do útero para a aceitação do embrião e a preparação das mamas para a secreção láctea. Em geral, a progesterona aumenta o grau da atividade secretora das glândulas mamárias e, também, das células que revestem a parede uterina, acentuando o espessamento do endométrio e fazendo com que ele seja intensamente invadido por vasos sangüíneos; determina, ainda, o surgimento de numerosas glândulas produtoras de glicogênio. Finalmente, a progesterona inibe as contrações do útero e impede a expulsão do embrião que se está implantando ou do feto em desenvolvimento.

As indicações terapêuticas dos estrogênios e progesterona são muito amplas e suas ações farmacológicas refletem, em grande parte, a amplitude de suas atividades fisiológicas. As indicações mais comuns desses fármacos são; a terapia de reposição hormonal para mulheres na pós-menopausa e a anticoncepção, mas os compostos específicos e as posologias usadas nessas duas situações são significativamente diferentes. Embora os anticoncepcionais orais sejam usados principalmente para evitar gravidez, tais fármacos também exercem efeitos benéficos significativos para a saúde, além da contracepção. Existem compostos naturais e sintéticos para uso oral e parenteral.

\subsection{Anticoncepção Hormonal}

\subsubsection{Anticoncepcional Hormonal Combinado Oral}

O Anticoncepcional Hormonal Combinado Oral (AHCO) consiste na utilização de estrogênio associado à progesterona, impedindo a concepção por inibir a ovulação pelo bloqueio da liberação de gonadotrofinas pela hipófise. Também modifica o muco cervical tornando-o hostil ao espermatozoide, altera as condições endometriais, modifica a contratilidade das tubas, interferindo no transporte ovular (GUYTON, 1998).

Existem diversos tipos de pílulas. As mais comumente receitadas são: 
- Pílulas Monofásicas: toma-se uma pílula por dia, e todas têm a mesma dosagem de hormônios (estrogênio e progesterona). Começa-se a tomar no quinto dia da menstruação até a cartela acabar. Fica-se sete dias sem tomar, durante os quais sobrevém a menstruação;

- Pílulas Multifásicas: toma-se uma pílula por dia, mas existem pílulas com diferentes dosagens, conforme a fase do ciclo. Por isso, podem ter dosagens mais baixas, e causam menos efeitos colaterais. São tomadas como as pílulas monofásicas, mas têm cores diferentes, de acordo com a dosagem e a fase do ciclo: não podem ser tomadas fora da ordem;

- Pílulas de Baixa Dosagem ou Minipílulas: têm uma dosagem mais baixa e contém apenas um hormônio (geralmente progesterona); causando menos efeitos colaterais. São indicadas durante a amamentação, como uma garantia extra para a mulher. Devem ser tomadas todos os dias, sem interrupção, inclusive na menstruação;

- Injetáveis: são anticoncepcionais hormonais que contém progesterona ou associação de estrogênios, para administração parenteral (intramuscular ou IM), com doses hormonais de longa duração. Consiste na administração de progesterona isolada, via parenteral (IM), com obtenção de efeito contraceptivo por períodos de 1 ou 3 meses, ou de uma associação de estrogênio e progesterona para uso parenteral (IM), mensal.

\subsection{Doenças periodontais}

As doenças periodontais são infecções causadas por microrganismos que colonizam a superfície dentária supra- ou subgengivalmente. Estima-se que cerca de 500 espécies diferentes de microrganismos são capazes de colonizar a cavidade bucal e que qualquer indivíduo pode abrigar 150 ou mais espécies diferentes. Embora as doenças periodontais apresentem certas características que são bem diferentes. A principal razão para essa particularidade é a característica anatômica incomum de uma estrutura mineralizada, o dente, passar através do tegumento, de modo que parte fica exposta ao ambiente externo enquanto a outra parte fica na intimidade dos tecidos conjuntivos (KINANE, et al., 2005).

As bactérias podem aderir ao dente propriamente dito, às superfícies epiteliais da gengiva ou bolsa periodontal, ao tecido conjuntivo subjacente, se exposto, e as outras bactérias já aderidas a essas superfícies. Ao contrário da superfície externa na maioria das partes do organismo, as camadas externas do dente não descamam, e, assim, a colonização microbiana é facilitada. Dessa forma, a situação é definida de modo que os microrganismos colonizam uma superfície relativamente estável, o dente, e são mantidos contínua e intimamente nas proximidades dos tecidos moles periodontais. Isso representa uma possível ameaça para esses tecidos e de fato para o hospedeiro.

Os microrganismos que causam doenças periodontais residem em biofilmes existentes nos dentes ou em superfícies epiteliais. O biofilme proporciona um ambiente de proteção aos microrganismos colonizadores e permite propriedades metabólicas que não seriam possíveis se as espécies existissem em um estado livre. O estabelecimento da doença é retardado por períodos prolongados após a colonização inicial pelo patógeno. Os agentes etiológicos, na maioria das vezes, parecem membros da microbiota indígena, e, assim, as infecções podem ser interpretadas como endógenas (CARRANZA JR et al., 2012).

Geralmente, a origem dos agentes infecciosos para um dado indivíduo é desconhecida, apesar de a transmissão pelos pais ou pessoas muito próximas exercer um papel fundamental. O que caracteriza principalmente essas doenças é o fato de que são causadas por microrganismo que residem 
em biofilmes fora do corpo. Seu tratamento é complexo, exigindo abordagens físicas, antimicrobianas e ecológicas (KINANE, et al., 2005).

\subsection{Características histopatológicas e clínicas}

A maioria dos indivíduos normais que mantêm uma excelente higiene bucal não é propensa a desenvolver doença periodontal avançada. Estudos clínicos experimentais de curta duração demonstraram que os microrganismos rapidamente começam a colonizar as superfícies dentárias limpas uma vez que a pessoa se abstenha da limpeza mecânica dos dentes; dentro de poucos dias, os sinais microscópios e clínicos de gengivite serão aparentes. Após 10 a 20 dias de acúmulo de placa, sinais clínicos de gengivite se estabelecem na maioria das pessoas, embora haja grandes variações, com alguns indivíduos sendo intrinsecamente resistentes e outros mais propensos à gengivite clínica. A gengivite é a forma mais comum das doenças gengivais.

A presença de sinais clínicos da inflamação gengival está confinada aos tecidos de proteção (gengiva livre ou marginal, gengiva inserida e papila interdentária) sem que tenhamos perda de inserção com comprometimento das estruturas de suporte periodontal (ligamento periodontal, cemento e osso alveolar). Em geral há uma intensificação do estado inflamatório à medida que a exposição à placa persiste. Há um aumento na exsudação do fluido e na migração dos leucócitos para os tecidos e sulco gengival. Clinicamente, esta lesão exibirá alteração de cor, forma, volume, aspecto superficial maior do que na "gengivite precoce".

À medida que há um aprofundamento da bolsa, ou seja, a placa prossegue em seu crescimento no sentido apical com o infiltrado inflamatório propagando-se no sentido do tecido conjuntivo, começa a ocorrer características diferentes importantes, como perda do osso alveolar, dano extenso às fibras, migração apical do epitélio juncional a partir da junção cemento-esmalte e manifestações disseminadas de danos inflamatórios e imunopatológicos aos tecidos, resultando na periodontite. Estas alterações inflamatórias são solucionadas ou revertidas quando se retomam as medidas adequadas para a limpeza dentária. Estudos clínicos de longa duração mostraram a importância da remoção do biofilme gengival para o tratamento bem-sucedido da doença periodontal em humanos (KINANE, et al., 2005).

A placa bacteriana tem sido defina como o fator etiológico primário para iniciação da doença periodontal. Contudo, são necessários patógenos periodontais para se desenvolver a doença, mas somente isso não é suficiente para o estabelecimento da doença (MASCARENHAS \& GAPSKI, 2003).

\subsection{Anticoncepcionais e a doença periodontal inflamatória}

Segundo PALMER \& SOORY (2005) as variações hormonais experimentadas pelas mulheres durante condições fisiológicas e não-fisiológica (tais como tratamento de reposição hormonal e uso de contraceptivos hormonais) resultam em alterações significativas no periodonto, particularmente na presença de inflamação gengival preexistente induzida por placa. A gengiva é o tecido - alvo para a ação dos hormônios esteroides Alterações clínicas nos tecidos do periodonto são identificadas durante os períodos de flutuação hormonal (puberdade, menstruação, gravidez e menopausa). Os efeitos do estrogênio e da progesterona sobre o periodonto têm recebido significativa atenção investigatória. Os principais efeitos desses hormônios sobre os tecidos periodontais podem ser resumidos como se segue:

○ O estrogênio afeta as peroxidases salivares, que atuam contra diversos microrganismos pela alteração do potencial de oxidação-redução; 
- O estrogênio possui efeito estimulador sobre o metabolismo de colágeno e angiogênese;

- O estrogênio pode desencadear as vias autócrinas ou parácrinas de sinalização do fator de crescimento polipeptídeo com efeitos que podem ser parcialmente mediados pelo próprio receptor de estrogênio;

- O estrogênio e a progesterona podem modular as respostas vasculares e a renovação do tecido conjuntivo no periodonto, associados à interação com mediadores inflamatórios.

Além dos efeitos sobre o periodonto, existem relatos de fatores de risco sistêmicos associados ao uso por tempo prolongado de contraceptivos hormonais. A correlação entre o uso dos contraceptivos hormonais e a doença cardiovascular associada a episódios tromboembólicos arteriais e venosos foi estudada e examinada no ano de 1996 (SOORY, 2000). O estrogênio é responsável pelos efeitos arterial e venoso, enquanto a progesterona afeta as alterações arteriais. As mulheres que usam contraceptivos orais mostram níveis plasmáticos elevados de diversos fatores de coagulação relacionados com a dose de estrogênio (WESTHOFF, 1996).

Os níveis aumentados dos fatores de VII $_{C}$ e XIIC são significativos, pois eles aumentam a probabilidade de coagulação, e, nos homens, esses fatores têm uma correlação fortemente positiva com a doença cardíaca sistêmica. Entretanto, o risco relativo depende da formulação contraceptiva usada e pode não ser uma plausibilidade biológica convincente para explicar essa associação (Davis, 2000).

Os efeitos desses hormônios na resposta tecidual são conhecidos por causarem aumento do exsudato gengival associado ao edema inflamatório. Característica esta, que vai de edema moderado e eritema até inflamação grave com hemorragia e hiperplasia gengival. Um aumento de $53 \%$ no volume do líquido gengival foi demonstrado em usuárias de contraceptivos hormonais comparadas ao grupo controle (LINDHE, 2005). Estudos observaram que a maioria dos efeitos pronunciados sobre a gengiva ocorreram nos três primeiros meses de tratamento contraceptivo, mas a dose de hormônios gestacionais foi mais elevada nas formulações mais antigas, comparadas com aquelas usadas atualmente, responsável por uma resposta mais intensa sobre os tecidos (DAVIS, 2000).

Outros efeitos intrabucais são as alterações salivares, como a diminuição na concentração de proteínas, ácido siálico, hexosaminas, fucose, íons hidrogênio e total de eletrólitos. O fluxo salivar mostrou-se aumentado num estudo realizado (MAGNUSSON et al., 1975) e diminuído em 30\% dos indivíduos em outro estudo (EL-ASHIRY et al., 1971).

Grande incidência de osteítes localizadas por extração dentária foi observada em mulheres que faziam uso de anticoncepcionais orais. Esse número maior de casos clínicos pode ser atribuído ao efeito do estrógeno do medicamento sobre os fatores da coagulação (SWEET \& BUTLER, 1977). Entretanto, a relação entre a ocorrência de osteíte e o uso de contraceptivos orais é inconclusiva devido a existência de estudos que refutam esses achados (COHEN \& SIMECEK, 1995).

A gengiva humana possui receptores para a progesterona e o estrogênio, fornecendo evidência que a gengiva é um alvo tecidual para ambos os hormônios gestacionais (CARRANZA JR et al., 2012). Em estudos in vitro de cultura de fibroblastos gengivais, o estrogênio aumentou a formação de metabólitos andrógenos anabólicos, enquanto a progesterona causou uma diminuição da resposta. Os efeitos combinados desses hormônios gestacionais sobre a produção de andrógenos foram menos pronunciados do que com estrogênio apenas, implicando uma ação mais catabólica da progesterona (TILAKARATNE \& SOORY, 1999). 


\section{ACTA \\ Biomedica Brasiliensia}

A progesterona aumenta a permeabilidade vascular, resultando na infiltração de leucócios polimorfonucleares e em níveis mais elevados de prostaglandina $\mathrm{E}_{2}$ no líquido gengival. A permeabilidade vascular aumentada pode ser induzida pelo estrogênio por estimular a liberação de mediadores como a bradicinina, a prostaglandina e a histamina. Entretanto, o controle do fluxo sanguíneo é o principal efeito do estrogênio. Portanto, a combinação de estrogênio e progesterona em pílulas contraceptivas pode contribuir para alterações vasculares na gengiva (MIYAGY et al., 1993).

Tem sido relatada a presença de mais exsudato no tecido gengival inflamado em mulheres que usam os contraceptivos orais do que nas gestantes. A gengivite resultante pode ser minimizada pelo estabelecimento de baixos níveis de placa no começo do tratamento com contraceptivos orais (ZACHARIASEN, 1993). Esta associação de estrogênio e progesterona é evidente e está na classificação recente das doenças periodontais (ARMITAGE, 1995), conforme abaixo:

- Gengivite associada à puberdade;

- Gengivite associada ao ciclo menstrual;

○ Gengivite associada à gravidez.

\subsection{Contraceptivos orais e a avaliação clínica}

No final de 1960 e início de 1970 publicou-se uma grande quantidade de artigos científicos descrevendo a relação da doença periodontal com os contraceptivos orais. Nesses estudos foram abordados a grande prevalência da inflamação gengival em mulheres que usavam os contraceptivos orais comparadas com as que não usavam (MARIOTTI, 1994).

No mesmo período, foram conduzidos estudos experimentais em humanos avaliando os efeitos dos contraceptivos orais na inflamação gengival (LINDHE, 2005). Usaram estrogênio e progesterona em dosagem de 2 a 20 vezes maior que os contraceptivos orais atuais (100 $\mu \mathrm{g}$ de estrogênio com 5 mg de progestina) e observaram mudanças nos tecidos gengivais. Esses resultados podem refletir parcialmente a dose mais elevada de hormônios gestacionais usados nas preparações contraceptivas mais antigas (PALMER \& SOORY, 2005).

Entretanto, um estudo em mulheres do Sri Lanka confirmou esses achados, mostrando níveis significativamente mais elevados de gengivite em usuárias de contraceptivos $(0,03 \mathrm{mg}$ de estradiol e $0,15 \mathrm{mg}$ de uma progestina) do que não - usuárias, apesar dos níveis semelhantes de placa bacteriana. Havia também significativa destruição periodontal naquelas que usaram injeção de progesterona (um preparado de $150 \mathrm{mg}$ de progesterona), 3 injeções mensais por 2-4 anos, comparadas com aquelas que usaram por menos de 2 anos (TILAKARATNE \& SOORY, 1999).

Esses achados podem ser atribuídos à duração de uso e aos efeitos da progesterona, que promove o catabolismo tecidual, resultando em maior perda de inserção periodontal. Entretanto, se os baixos níveis de placa forem estabelecidos e mantidos durante o uso, esses efeitos podem ser minimizados (PALMER \& SOORY, 2005).

Outros estudos onde usaram contraceptivos orais com diferentes taxas de estrogênio e progesterona foram avaliados o índice de placa bacteriana e o índice de inflamação gengival. Como resultado obtiveram um índice de inflamação gengival alto nas mulheres que faziam uso dos contraceptivos orais; e nas margens gengivais onde a placa bacteriana manteve-se presente e as mulheres não faziam uso dos anticoncepcionais o índice de inflamação gengival foi baixo (MAGNUSSON et al., 1975). 


\section{ACTA

Todavia, um estudo recente refuta essas concepções, onde foram usados medicamentos anticoncepcionais com baixa dosagem de hormônios e não houve nenhum aumento no risco da mulher desenvolver a doença periodontal ou ter alteração no curso da doença. Este estudo reforça então, que as baixas dosagens de hormônios não causam uma ameaça significante nos tecidos periodontais das mulheres (PRESHAW et al., 2001).

Outras pesquisas não encontraram nenhuma diferença significativa no índice de placa e índice gengival, em relação entre mulheres usuárias de contraceptivos e o grupo controle. Porém, notaram que mulheres que usaram o contraceptivo por mais de um ano e meio exibiram destruição periodontal maior do que o grupo controle de idade e higiene oral comparáveis, apresentando assim um maior índice gengival (KNIGHT \& WADE, 1974). A presença de fatores irritantes locais associada a péssimas condições de higiene oral pode resultar na exacerbação da resposta inflamatória gengival, frente ao biofilme dental, em usuárias de pílula anticoncepcional (PALMER \& SOORY, 2005).

As postulações foram corroboradas por SANTOS et al., (2008) que conduziram pesquisa para avaliar a influência da ação dos contraceptivos hormonais sobre os tecidos periodontais. Relataram que no tocante à concentração hormonal, a pesquisa revelou que drogas com concentrações mais elevadas, seja de estrógeno ou de progesterona, não aumentaram os riscos de ocorrência da doença periodontal. Concluíram que o tempo de uso de contraceptivos hormonais, bem como diferenças nos tipos e concentrações hormonais de estrógeno e progesterona não representaram grandes mudanças na condição periodontal das mulheres usuárias da droga.

Baseado na literatura revisada, conclui-se que os contraceptivos orais usados entre as décadas de 1960 e 1970 provocavam alteração nos tecidos periodontais (inflamação gengival moderada à grave, aumento do exsudato gengival e hiperplasia gengival), provavelmente devido as altas concentrações de estrogênio e progesterona na composição desses medicamentos.

Atualmente, os contraceptivos orais parecem não interferir nos tecidos periodontais de indivíduos com a doença periodontal preexistente. Isso ocorre, provavelmente, devido às baixas concentrações hormonais contidas nos anticoncepcionais atuais. Entretanto, é possível diagnosticar mulheres com inflamação na margem gengival que não respondem ao debridamento e higienização caseira. Por isso, a anamnese cuidadosa é uma ferramenta fundamental para estabelecer correlações patológicas, planejamento e condução terapêutica eficiente.

\section{Conclusão}

Apesar de todas as alterações gengivais causadas pelo uso dos contraceptivos orais, o fármaco não é o agente etiológico, e sim um potencial inflamatório. O fundamental é manter o tecido periodontal hígido, ou seja, ausente de placa bacteriana. Preservada essa condição, a paciente poderá fazer uso de contraceptivos orais sem deleção do tecido periodontal.

\section{Referências}

AMERICAN SOCIETY OF REPRODUCTIVE MEDICINE. Hormonal contraception: recent advances and controversies. Fertility and Sterility 2004; 82(1):26-32.

ARMITAGE, G.C. Development of a classification system for periodontal diseases and conditions. Annals of Periodontology, v. 4, p. 1-6, 1999.

CARRANZA Jr., F.A.; NEWMAN M.G.; TAKEI H.H. Periodontia clínica, 9 ed., Ed. Guanabara Koogan, Rio de Janeiro, 2004. 
COHEN, M.E.; SIMECEK, J.M. Effects of gender- related factors on the incidence of localized alveolar osteitis. Oral Surg Oral Med Oral Pathol Radiol Endod, v.79, n.4, p.416-422, 1995.

CORMACK DH. O Sistema Reprodutor Feminino. In: Fundamentos de Histologia. Rio de Janeiro: Guanabara Koogan; 1993. p 291-306.

DAVIS, A. J. Advances in contraceptive (review). Obstetrics and gyneacology clinics of North America, v. 27, p. 597-610, 2000.

EL-ASHIRY, G. M., EL-KAFRAWY, A. H., Nasr, M. F. \& Younis, N. Effects of oral contraceptive on the gingiva. Journal Periodontology, v.42, n.5, p.273-275, 1971.

GOLDMAN, H.M.; COHEN, D.W. Periodontia. 6a ed. Rio de Janeiro. Guanabara Koogan, 1983. 1094p.

GUYTON AC. Sistemas reprodutivos masculino e feminino e seus hormônios. In: Fisiologia Humana. GUYTON AC. 6 ed. Rio de Janeiro: Guanabara Koogan; 1988. p 498-512.

KALKWARF, K.L. Effects of oral contraceptive therapy on gingival inflammation in human. Journal Periodontology, v.49, n.11,p.561-563, 1978.

KINANE, D.F.; BERGLUNDH, T.; LINDHE, J. Interações entre Parasita e Hospedeiro na Doença Periodontal. In: Lindhe, J.; Karring, T.; Lang, N.P.: Tratado de Periodontia Clínica e Implantologia Oral. $4^{\mathrm{o}}$ edição. Cap. 5, p.148-175, 2005.

KNIGHT, G.M.; WADE, B.A. The effect of hormonal contraceptive on the human periodontium. Journal of Periodontal. Research, v.9, p.18-22, 1974.

LINDHE, J. Tratado de periodontologia clínica e implatologia oral, 4 o ed., Ed. Guanabara Koogan, Rio de Janeiro 2005.

LOOSE-MITCHELL, D.S.; SYANCEL, G.M. Estrogênios e Progestogênios. In: Goodman e Gilman: As Bases Farmacológicas da Terapêutica. 10 edição. Cap. 58, p.1201-1225, 2003.

MAGNUSSON, T.; ERICSON, T.; HUGOSON, A. The effect of oral contraceptives on the concentration of some salivary substances in women. Arch Oral Biol, v.20, n.2, p.119-126, 1975.

MARIOTTI, A. Sex steroid hormones and cell dynamics in the periodontium. Crit Rev Oral Biol Med, v.5, p. 27-53, 1994.

MASCARENHAS, P.; GAPSKI, R.; AL - SHAMMARI; et al. Influence of sex hormones on the periodontium. Journal of Clinical Periodontology, v.30, p.671-681, 2003.

MIYAGY, M., AOYAMA, H.; MORISHITA, M.; IWAMOTO, Y. Effects of sex hormones on production of prostaglandin $\mathrm{E}_{2}$ by human peripheral monocytes. Journal of Periodontology, v. 64, p. 1075-1078, 1993. 
PALMER R, SOORY M. Fatores modificadores: diabetes, puberdade, gravidez e menopausa e tabagismo. In: Tratado de Periodontia Clínica e Implantologia Oral. LINDHE J. 4 ed. Rio de Janeiro: Guanabara Koogan; 2005. p 176-193.

PRESHAW, P.M.; KNUTSEN, M.A.; MARIOTTI, A. Experimental Gingivitis in Women Using Oral Contraceptive. Journal Dentistry Research, v.80, p.2011-2015, 2001.

SANTOS, PAT; FORTES, TMV; CABRAL, MCB; NOVAES, SMA. Influência dos hormônios sexuais sobre os tecidos periodontais em usuárias de contraceptivos hormonais. R. Periodontia. 2008, 18(1):55-63.

SOORIYAMOORTHY, M.; GOWER, D.B. Hormonal Influences on gengival tissues: relationship to periodontal disease. Journal Clinical Periodontology, v.16, n.4, p-201-208, 1989.

SOORY, M. Targets for steroid hormone mediated actions of periodontal pathogens, cytokines and therapeutic agents: some implications on tissue turnover in the periodontium. Current Drugs Targets, 1(1):309-325, 2000.

STAFFOLANI, N.; GUERRA, M.; PUGLIESE, M.; CARDINALE, G.; GULINO, A. Hormonal receptors in gingival inflammation. Minerva stomatologia, v. 38, p. 823-826, 1989.

STEINBERG BJ. Saúde bucal das mulheres. Compendium de Educação Continuada em Odontologia: Mulheres e Odontologia 2001. ed. especial; 22(1):8-14.

SWEET, J.B.; BUTLER, D.P. Increase incidence of postoperative localized osteitis in mandibula 3 rd molar surgery associated with patients using oral contraceptives. Amj Obstet Gynecol, v.127, n.5, p.518-519, 1977.

TILAKARATNE, A. \& SOORY, M. Modulation of androgen metabolism by estradiol- $17 \beta$ and progesterone, alone and in combination, in human gingival fibroblasts in culture. Journal of Periodontology, v. 70, p. 1017- 1025, 1999.

TUNES, V.R.; RAPP, G.E. Influência das condições sistêmica sobre as doenças periodontais: atualização em periodontia e implantodontia. São Paulo: Artes Médicas, 1999.

VITTEK J, MUNNANGI PR, GORDON GG, RAPPAPORT SC \& SOUTHREN AL. Progesterone receptors in human gingival. IRCS, Medical Science, v. 10, p. 381, 1982.

WESTHOFF, C. L. Oral contraceptives and venous tromboembolism: should epidemiological associations drive clinical decision making? Contraception, v. 54, p. 1-3, 1996.

ZACHARIASEN, R.D. The effect of elevated ovarian hormones on periodontal health: oral contraceptives and pregnancy. Women Health, v.20, n.2, p.21-30, 1993. 